\title{
Multimedia Instructional Module for the Arts and Culture Subject Applied to Middle School Students
}

\author{
Adriana E. Prado Malte ${ }^{1, *}$, Erick P. Herrera-Granda ${ }^{2}$, Israel D. Herrera-Granda ${ }^{2}$, \\ Maritza G. Méndez-Ortega ${ }^{1}$ \\ ${ }^{1}$ Técnica del Norte University, Av. 17 de Julio and José Córdova 5-21, Ibarra, Ecuador \\ ${ }^{2}$ Engineering Faculty in Applied Science -UTN-Técnica del Norte University, Av. 17 de Julio, 5-21, and Gral. José María \\ Córdova Ibarra, Ecuador
}

Received March 21, 2020; Revised June 3, 2020; Accepted January 25, 2021

\section{Cite This Paper in the following Citation Styles}

(a): [1] Adriana E. Prado Malte, Erick P. Herrera-Granda, Israel D. Herrera-Granda, Maritza G. Méndez-Ortega , "Multimedia Instructional Module for the Arts and Culture Subject Applied to Middle School Students," Universal Journal of Educational Research, Vol. 9, No. 3, pp. 702 - 712, 2021. DOI: 10.13189/ujer.2021.090330.

(b): Adriana E. Prado Malte, Erick P. Herrera-Granda, Israel D. Herrera-Granda, Maritza G. Méndez-Ortega (2021). Multimedia Instructional Module for the Arts and Culture Subject Applied to Middle School Students. Universal Journal of Educational Research, 9(3), 702 - 712. DOI: 10.13189/ujer.2021.090330.

Copyright $@ 2021$ by authors, all rights reserved. Authors agree that this article remains permanently open access under the terms of the Creative Commons Attribution License 4.0 International License

\begin{abstract}
Middle School and High School education in Ecuador focuses on integrating educational innovation in the pursuit of educational prosperity based on government projects that sustain proper use of educational technology. The main objective of this research is the implementation of a multimedia instructional module for the subject of arts and culture applied to middle school students of the Educational Institution Eugenio Espejo, which serves as a tool for enhanced significative learning. This project was performed through three phases. First, the pedagogic methodology used by the teachers of the subject was diagnosed. Next, the development of the multimedia instructional module in the portable software eXeLearning INTEF-eXe Project version 2.2 was carried out. Finally, a statistical analysis was performed on the results obtained from the qualitative evaluation before and after the implementation of the multimedia instructional module, using the statistical programming language $\mathrm{R}$, applying MANOVA, ANOVA and Paiwise T-tests in order to demonstrate the differences between the variables obtained from the grades of each partial. The study of the results performed in the average partial grades of the eighth, ninth and tenth grades, in a sample of $\mathrm{n}=348$ students demonstrates progressive improvement of the student grades, which demonstrates that students are motivated to work with educational technology, even in regions that have limited internet access, which is encouraging since it allows updating students' technological skills that meet
\end{abstract}

today's demanding learning standards.

Keywords Education Technology, Innovation, eXe-Learning, Instructional Module, Basic General Education

\section{Introduction}

Throughout education history, there have been educational processes in diverse fields. Learning environments have been established in most countries to facilitate disciplines like the ecclesiastic and metaphysics seeking to perfect humanity [1]. Consequentially, pedagogic science originates with the aim of enhancing learning processes and defines "practice" as a student-teacher activity using enrichment-learning methodologies and strategies. [2] However, learning practices have experienced regular changes created by science and technology which have been adopted by educational practices so as to innovate learning in a developing society.

Simultaneously to such learning changes, society welcomes innovation as a result of the accelerating global growth along with the technological boom of belonging to each decade that fuses technology and education. As a result, nowadays every person in the world owns a 
basictech device for communication and learning not limited to help them organize their everyday lives in some way or other.

In regards to growth and development, Ecuador's government decisively accepts the transformation of learning practices. Therefore, it is planning to include this transformation in public policy according to the Republic Constitution, fifth section, article 27 that states "to guarantee quality education by promoting the performance of the arts [3]. Thus, the National Educational Project related to compulsory education levels presents the subject "Cultural and Artistic Education" in a learning-space where students will be able to observe, explore and express themselves, to include peer-interaction founded on tolerance and inclusiveness. Therefore, training independent students focused on acquiring knowledge in order to meet scientific and technological advances suitable for their generation is essential.

In this case, the Ministry of Education presents pedagogic guidelines to provide training in the use of Open Digital Learning Resources- to educators so that the application of technological methodologies may be used in classrooms. [4] The Constitution of the Republic of Ecuador in 2008, article 347, fifth section, literal one states, "Ensuring permanent quality improvement, extensive broadband together with infrastructure and equipment needed at educational institutions" (p.127). Included is the "Information and Knowledge Society Plan” 2018-2019 and the effective use of technology in several sectors as enhancing strategy for the new Information and Knowledge Society with the purpose of promoting national prosperity. [5].

Indeed, TICs are widely used in personal and professional relationships while there is evidence that educational framework applications require more strict instruction of competencies for future professionals and education university actors interact through social networks to include virtual learning platforms so that multimedia didactic material is integrated to vast online resources accessible by students.

Opposite to superior education processes, elementary, middle and high school Ecuadorian education system, the focus is constructivist and positions students as the learning focus while educators take the role of facilitators. Unlike education in developing countries which take a connectivity pedagogic model like the one George Siemens presented in 2005 implies the use of a series of tools and digital didactic material to perfect students' skills in learning process. [6].

Supported by innovative models, education technology emerges prioritizing the use of software for multimedia instructional model implementation that not only improves student-professor interaction, but also provides prompt content feedback promoting acquired knowledge retention leading to significant learning. Furthermore, hybrid or mixed courses where the cognitive process involves face-to-face classes, complement instruction online modules and consequently, students have control of their learning pace by the use of instructional videos that further testing in each section of study instilling up to $13 \%$ higher score motivation in final exams performance compared to first tests sitting. [7].

For one thing, the lack of student-teacher interaction challenge produced mistrusting feelings regarding computer-assisted learning six years ago [8]. In the same context, printed instructional modules aiming to decrease cognitive workload so that memorizing and attention abilities are enhanced, also use color-coded full-screen images and sectioned text contributing to a decrease in students' cognitive effort. [9].

Recent research reveals that crossword virtual-supported classes make students commit to their own learning, benefiting from physical and online tools that keep them focused until a solution for a particular formulated problem is found. [10]. It is also proven that Financial Data Computational Statistics educational projects and learning innovation systems, develop software based instructional designs that have complex mathematical calculations in self-regression multivariate models —VAR—random asymmetry testing in addition to showing electronic instructional module in students training, resulting in optimum data gathering and improved information understanding [11].

Furthermore, this study used exe-learning software for the creation of educational learning addressing learning processes from different views as in [12], [13],[14] objective learning research for the understanding of function-operation obtaining progress in knowledge-acquisition thus, generating autonomy in the process. Not only students get training to develop technological skills, but also training includes professional performance with the use of attention keeping techniques at students own study-pace.

Giving access to digital tools with authentic scopes, this research aims to become a learning tool enhancing a learning experience and creating awareness of Cultural and Artistic Education at "Eugenio Espejo Middle School" which has pedagogic limitations with the use of technological pedagogic material. What is more, 161 students benefited from the learning process applied in rural areas. Additionally, education progress will boost an information- society demanding its inhabitants the learning of new abilities so that innovation changes may be successfully faced [15].

This research aimed to implement an instructional multimedia learning module to a Cultural and Artistic Education program at "Eugenio Espejo Middle School", located in San Juan de Lanchas sector in the Mira city, as a tool for improving significative learning, includes an institutional scope suitable to train students able to meet today's labour skills as part of a technologically demanding society, working efficiently to integrate these young students into Ecuador's government comprehensive plan called "A whole life".[16]. 


\section{Methodology}

A three-phased blended-descriptive approach was applied to this investigation:

\subsection{Pedagogic Practice "The Arts and Culture Program” Applied to Middle School Students of the Eugenio Espejo Educational Institution}

This institution adopts the constructivist pedagogic model founded on socio-critic Piaget, Ausubel, Bruner, Gagné and Vigosky theories, which position students as the learning focal point, whereas the Arts and Culture epistemologist model has a comprehensive and holistic approach training educator to perform a variety of activities.

Furthermore, The Arts and Culture program connects multidisciplinary skills as a personal development strategy focusing on math's, language and technology so students develop a sense of identity though a human cognition process [17] [18] having a positive impact on academic performance. Having said that, global pedagogic practice establishes information and communication technologies-ICT_as enhancing learning tools so that individuals have innovative abilities readily available for today's knowledge-society.

Similarly, educators make use of technology in the classroom, at all levels of education particularly from elementary to High School education complying with national education programs according to the degree of difficulty and skills presented at each education level.

\subsection{Multimedia Instructional Development Module Applied to the Arts and Culture Program at Middle School Students}

After a systematic analysis was done, portable software called “eXeLearning INTEF-eXe” Project version 2.2. was set for the application of multimedia didactic material at the length of the research through an

ADDIE method so as to follow the multimedia instructional model's analysis, design, implementation and evaluation phase [19].

First, the analysis phase was done through a diagnostic evaluation to define students' previous knowledge of the subject and their social and family general characteristics, including students learning styles. Next, the development and design phase include twelve teaching hours given and the application of institutional methodologies.

At the implementation phase, academic praxis from formulated academic material, together with students training took place daily. Then, during the first four months_each academic module's duration-eXeLearning is implemented as a pedagogic tool which executes the instructional multimedia module alternatively. During the second and third academic modules, the use of the software connected to multimedia academic material is maximized.
Finally, an alternative summative evaluation for each academic module was done for research continuation purposes.

\subsection{Multimedia Instructional Module Statistical Analysis Performed, on the Data Before and after the Implementation, through Statistic Programing Language “ $R$ ”}

A 34-question survey was conducted with the purpose of determining the need for the implementation of a multimedia instructional module. Questions based on four main elements such as the need for such instructional module, determining the importance of the application of this module on "The Arts and Culture" program, methodology applied by educators, students' current work-study conditions and time spent on academic assignments. Last, the role played by social networks and parental help.

A $n=348$ sampling was applied to the survey comprised by elementary to high school students. Results were processed through statistical professional software R. Construct Validation used an Statistical Confirmatory Factorial Analysis technique-CFA-which simultaneously analyses a set of variables [20], apart from seeking performance patterns to validate each factor [22] [23]. This technique analyzes the fact that unique-factors belong to a single construct.

Initially, a data treatment was conducted to stress atypical observations having a 66.24 score "cut-off” level based on Mahalanobis distances that each survey has related to a multivariate observation's centroid. Through this process 27 surveys were eliminated since they were out from 99.9\% Chi-Square quintile distribution range. In this way, the main data base is now composed by $n=321$ observations.

Activity, linearity, normality, homogeneity and homoscedasticity qualities were tested in order to verify the possibility of applying parametric testing on the sample. Figure 1.

Assumption verification was conducted through a multivariate false regression analysis. Figure 1a shows the correlation matrix for all of the possible pair of variables. However, none of the pairs reached any proximate correlation 1 or -1 securing additivity assumption. On the other hand, figure $1 \mathrm{~b}$ shows standardized quintiles histogram for the sample. Additionally, it was observed that statistics between -2 to 2 follow normal distribution, thus securing normality levels. Figure $3 b$ shows sample Q-Q plot of the sample quantiles vs. theoretical Chi-Square quintiles which follow a lineal path, thus securing linearity assumption. Finally, under Barlett's sphericity criteria, in figure $1 \mathrm{~d}$, homogeneity and homoscedasticity are secured as long as the set quintiles are similarly distributed over the four quadrants forming a random interspersed. 


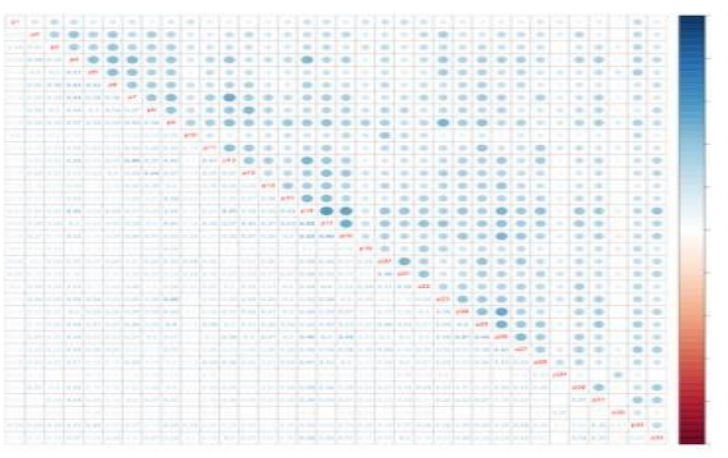

a)

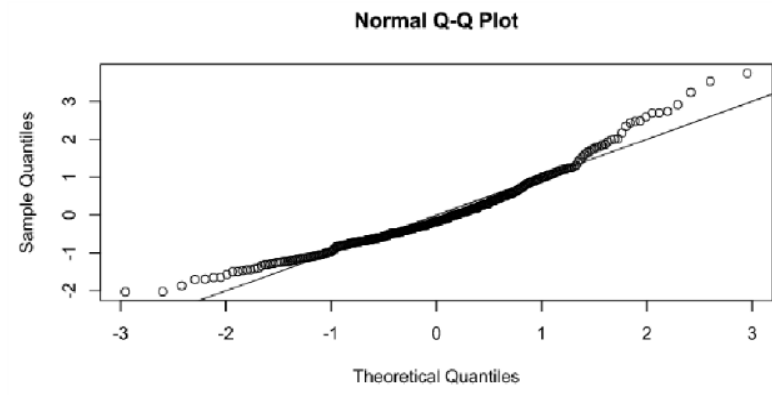

c)

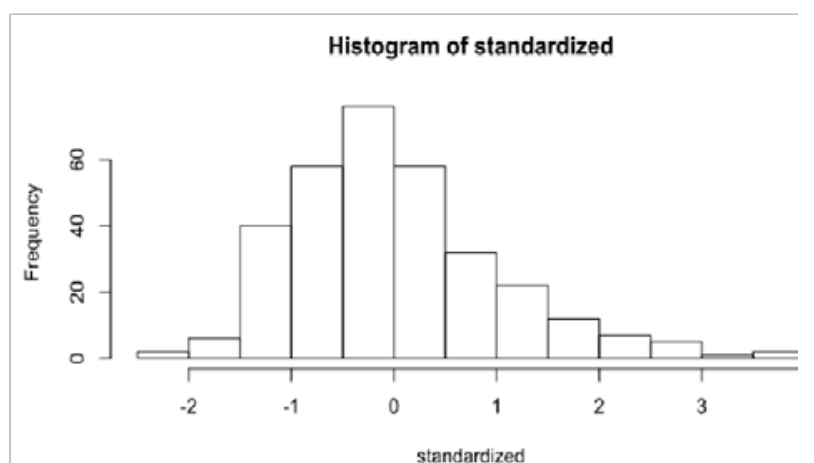

b)

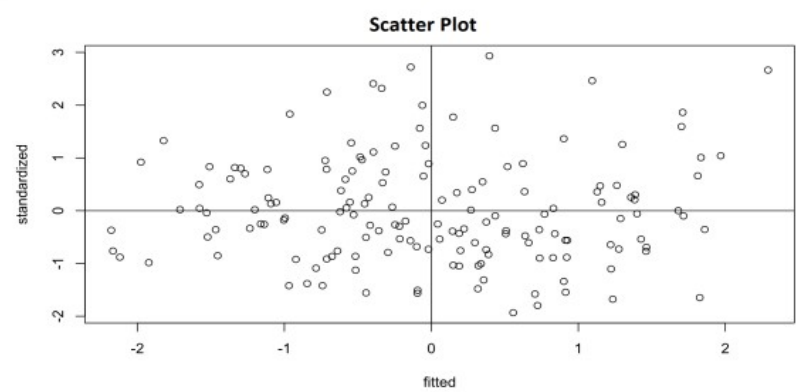

d)

a) Activity b) Normality, c) Linearity, d) Homogeneity and Homoscedasticity

Figure 1. Assumption analysis

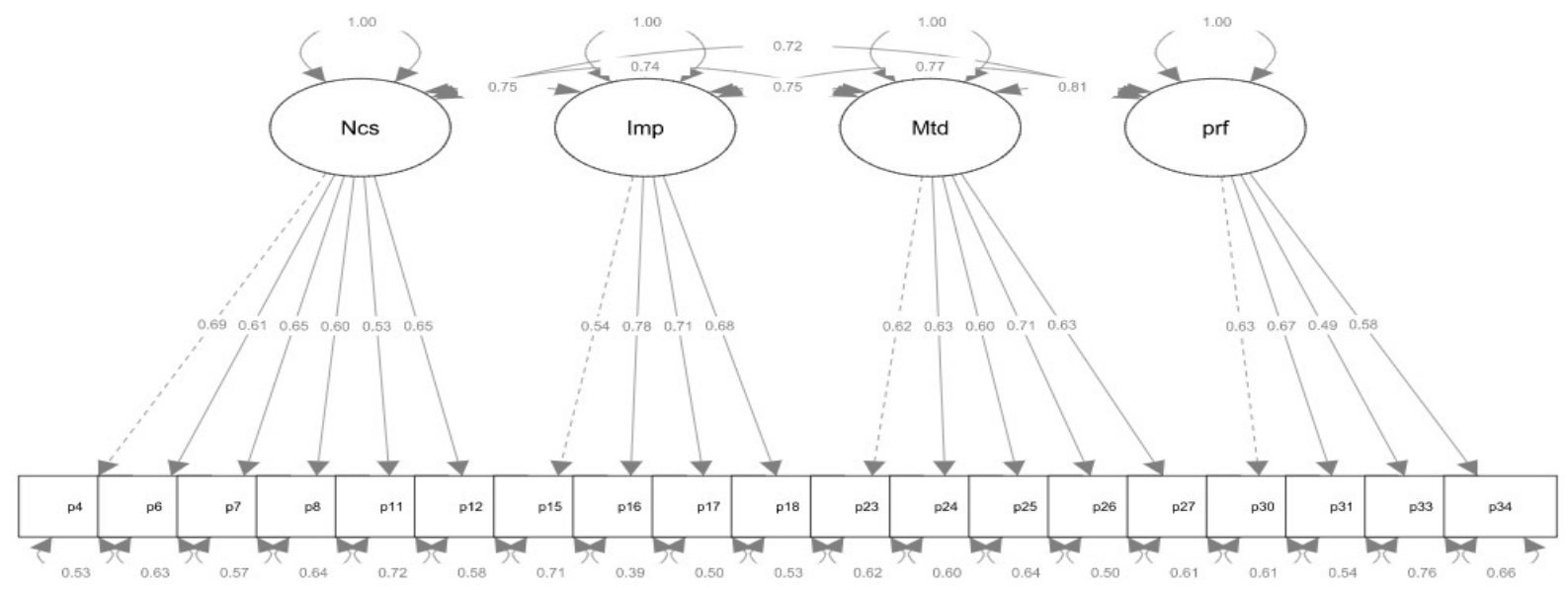

Figure 2. Survey Validation

Later, after presumption verification, a Confirmatory Factorial Analysis - CFA - was executed in Rstudio which initially, shows structural saturation and correlation through a path-diagram. Taking into account questions 1, 2, $3,5,9,10,13,14,19,20,21,22,28,29,32$ did not have enough saturation which was less than 0.3 (Figure 2), thus they were removed from the factorial structure suggesting that such questions do not have an objective performance pertaining to each factor's quantification. While the accepted remaining 19 questions creates a final factorial model since its saturation levels are close or higher than 0.5 (Table 1).

As seen in Fig. 2 final factorial structure doesn’t present any invalidity saturation-correlation signs between factors. Moreover, Table 1 demonstrates goodness of fit indexes obtained from CFA where it is evident that CFI, NNFI and TLI reached values over 0.9 in contrast to SRMR which value is lower than 0.05 concluding that data gathered in the survey is valid and reliable. Furthermore, the factorial analysis through its saturations, weighed more appropriately the level of relevance each question has in the factorial structure resulting in a "need, relevance, methodology and performance issues factors. The obtained weighted averages are shown in Table 5, which corresponds to the balanced structure outcome.

Based on the weighted factors, the importance (which 
achieved scores of $78.29 \%$ and $80 \%$ ) of the technological implementation was justified, and therefore Exelearning software was chosen as a daily pedagogic tool applied to The Arts and Culture program at Middle School levels using ICT as the program's focal point [21].

In this context, the multimedia instructional model applied incipiently to the first and following academic period resulting in the model's optimum use from October 2019 to February 2020 academic year. In order to demonstrate implementation efficacy, students' marks from each academic period were used to execute a multivariate statistical analysis applying MANOVA, ANOVA and Pairwise T-Tests using average data from three month-academic periods applied to the different strata of Middle School students.
To enter data into the new database, normality, linearity, homogeneity and homoscedasticity presumption levels were verified, using the previously mentioned multivariate analysis. Additionally, the correlation between each pair of variables for the obtained marks in the three academic periods was analysed Fig. 3. Next, the correlations obtained through the Pearson method resulted all positive showing $\mathrm{p}$-values over 0.2 being then, positioned in moderate correlation levels, clearly validating a growing tendency in students' marks, specifically over time.

Fig.3. Presents a multivariate correlation, density, histogram and dispersion matrix for the three -academic grading period applied to the student grades demonstrating a growing tendency for student grades in each academic period, thanks to the implementation of Exelearning.

Table 1. Confirmatory Factorial Analysis

\begin{tabular}{c|c|c|c|c|c}
\hline npar & Fmin & chisq & Df & Pvalue & baseline.chisq \\
44.000 & 0.466 & 299.013 & 146.000 & 0.000 & 2143.231 \\
\hline baseline.df & baselinepvalue & $c f i$ & $t l i$ & Nnfi & Rfi \\
171.000 & 0.000 & 0.922 & 0.909 & 0.909 & 0.837 \\
\hline$n f i$ & Pnfi & $i f i$ & $r n i$ & Logl & unrestricted.longl \\
0.860 & 0.735 & 0.923 & 0.922 & -9125.265 & -8975.728 \\
\hline aic & Bic & ntotal & bic2 & Rmsea & rmsea.ci.lower \\
18338.530 & 18504.473 & 321.000 & 18364.912 & 0.057 & 0.048 \\
\hline rmsea.ci.upper & rmsea.pvalue & rmr & rmr_nomean & Srmr & smr_bentler \\
0.066 & 0.100 & 0.074 & 0.074 & 0.047 & 0.047 \\
\hline srmr_bentler_nomean & crmr & crmr_nomean & srmr_mplus & srmr_mplus_nomean & cn_05 \\
0.047 & 0.049 & 0.049 & 0.047 & 0.047 & 189.080 \\
\hline cn_01 & gfi & agfi & pgfi & Nfi & ecvi \\
\hline
\end{tabular}

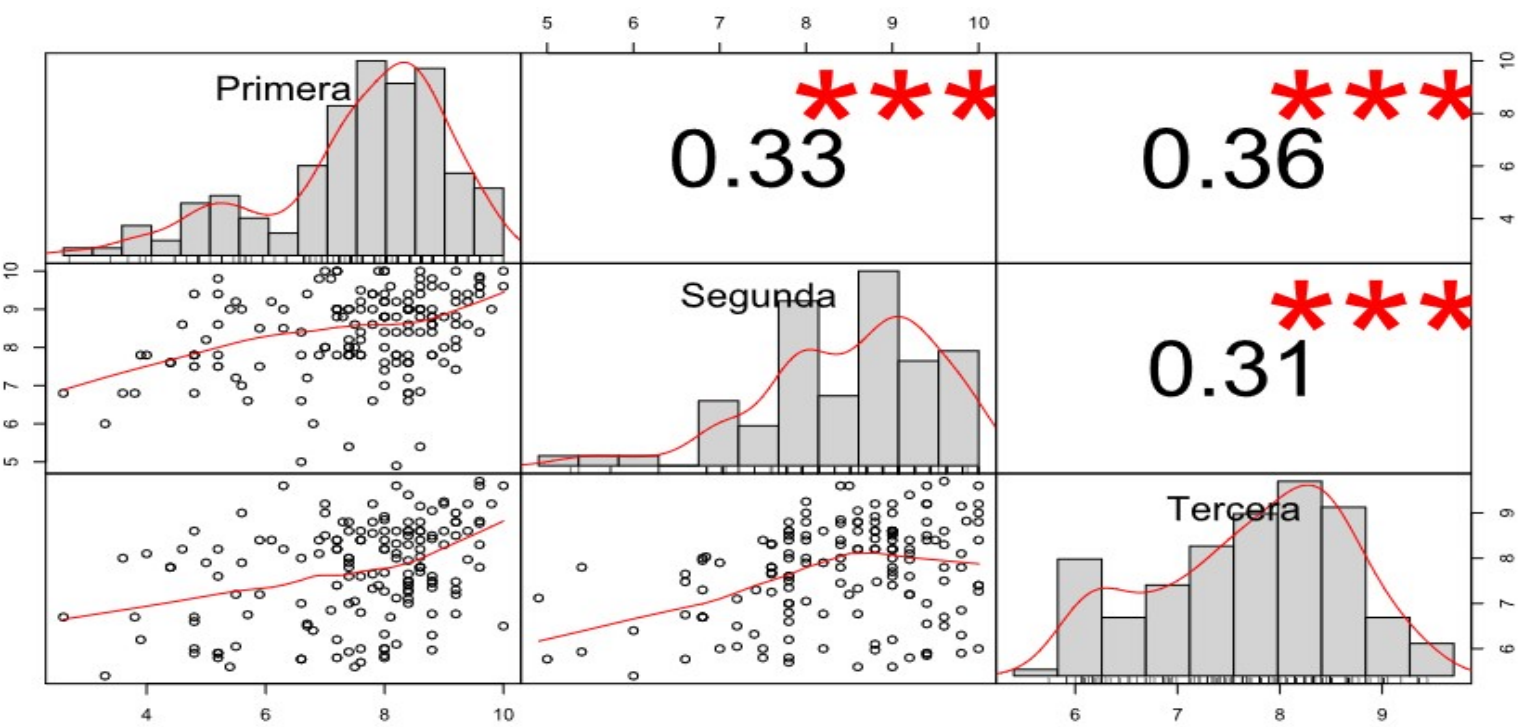

Figure 3. Additivity and Correlation 
Table 2. MANOVA test results for the three grading periods

\begin{tabular}{|c|c|c|c|c|c|c|}
\hline Multivariate Tests Mark & Df & Test stat & Approx F & Num Df & Den Df & $\operatorname{Pr}(>\mathrm{F})$ \\
\hline Pillai & 2 & 0.5230594 & 18.06168 & 6 & 306 & $<2.22 \mathrm{e}-16^{* * *}$ \\
\hline Wilks & 2 & 0.5404524 & 18.25307 & 6 & 304 & $<2.22 \mathrm{e}-16^{* * *}$ \\
\hline Hotelling-Lawley & 2 & 0.7327858 & 18.44178 & 6 & 302 & $<2.22 \mathrm{e}-16^{* * *}$ \\
\hline Roy & 2 & 0.4957290 & 25.28218 & 3 & 153 & $2.4316 \mathrm{e}-13^{* * *}$ \\
\hline Signif. codes: & 0 & ‘***, $\quad 0.001$ & ‘**, $\quad 0.01$ & 0.05 & ‘' & ، 1 \\
\hline
\end{tabular}

Table 3. Results from ANOVA uni-varied and Levene tests from each 4-month period

\begin{tabular}{|c|c|c|c|c|c|c|c|}
\hline \multicolumn{4}{|c|}{ One-way ANOVA } & \multicolumn{4}{|c|}{ Levene's test for Homogeneity of Variance (center = mean) } \\
\hline Factor & DFn / DFd & $\mathrm{F}$ & p-value & $\mathrm{p}<0.05$ & $\mathrm{~F}$ & p-value & $\mathrm{p}<0.05$ \\
\hline $\begin{array}{c}\text { First grading } \\
\text { period }\end{array}$ & $2 / 154$ & 3.590544 & $0.02991653 *$ & Significant & 4.719611 & $0.01024853^{*}$ & Significant \\
\hline Factor & DFn / DFd & $\mathrm{F}$ & $\mathrm{p}$-value & $\mathrm{p}<0.05$ & $\mathrm{~F}$ & p-value & $\mathrm{p}<0.05$ \\
\hline $\begin{array}{c}\text { Second grading } \\
\text { period }\end{array}$ & $2 / 154$ & 20.31701 & $1.476563 \mathrm{e} 08^{* * *}$ & Significant & 8.562588 & $0.000297799 * * *$ & Significant \\
\hline Factor & DFn / DFd & $\mathrm{F}$ & $\mathrm{p}$-value & $\mathrm{p}<0.05$ & $\mathrm{~F}$ & $\mathrm{p}$-value & $\mathrm{p}<0.05$ \\
\hline $\begin{array}{c}\begin{array}{c}\text { Third grading } \\
\text { period }\end{array} \\
\end{array}$ & $2 / 154$ & 11.46381 & $2.284722 \mathrm{e} 05^{* * *}$ & Significant & 15.66297 & $6.427009 \mathrm{e} 07 * * *$ & Significant \\
\hline Significance codes: & & 0 & ‘***, & ‘**, & 0.05 & ‘' & ، \\
\hline
\end{tabular}

According to Wilks, Pillai, Hotelling-Lawley and Roy largest root multivariate correlation, executed through MANOVA test in R, there were high levels of significance in each period as seen in Table 2. Based on Pillai Wilks and Hotelling-Lawley principles, the sampling shows p-values lower than 0.05 therefore, it is confirmed that there exist significant differences in the multivariate sample. Also, a $2.4316 e-13$ p-value for Roy's largest root was obtained, suggesting that a uni-varied ANOVA analysis has to be applied to each academic period marks.

Next, a one-way ANOVA test for each of the performance average from each grading period was conducted. Significant differences among Middle School student were found for each variable among strata, which gave way to analysing the existing differences for the acceptance and efficacy of the implementation, specifically applied to students of different grades. ANOVA test results are shown in Table 3.

Table 3 shows significative differences in each variable that establishes the three academic period's marks. Then, in order to define the existence of significative differences in strata for each grading period, a Pairwise T-Test was applied and the results are shown in Table 4.

As seen in Table 4 each grading period shows significative differences among students marks in particular these differences were found over the different academic periods for the eighth ninth and tenth grades contrasting different acceptance levels for the instructional module implementation. Regarding to the applied pairwise T-Tests, it is safe to say that during the first academic period, eight grade students' academic performance was notably better than tenth grade students' performance (0.037 p-value). Moreover, in the second period, eighth grade students showed better academic performance levels than ninth grade students and ninth grade students performed better than tenth grade students $(0.00038$ and 1.1e-09 p-values respectively). Finally, the third academic period tenth grade students had better academic performance than eighth and ninth grade students (1.6e-05 and $0.00064 \mathrm{p}$-values respectively).

In order to visualize how students gradually adapted to module's implementation over time, the data base was transposed so that the changes could be compared to each grading period per grade. Therefore, the new strata used in the multivariate analysis are the marks obtained from each student from the first second and third grading periods. So, the new dependent variables studied at the second analysis phase were the grades of the students of eighth, ninth and tenth grade.

Therefore, MANOVA and ANOVA were executed again followed by a Pairwise T-Test analysis for each possible pair of strata, following the same previously applied methodology.Results are shown in tables 5, 6 and 7. 
Table 4. Pairwise T-Test’s applied to each grading period

\begin{tabular}{|c|c|c|}
\hline \multicolumn{3}{|c|}{ Pairwise T-Test first academic period } \\
\hline & Tenth grade & Ninth grade \\
\hline Ninth grade & $\begin{array}{l}p-\text { value }=0.87 \\
\text { Not significant } \\
\overline{x N \text { inth }}=7.38, \sigma \text { Ninth }=1.74 \\
\bar{x} \text { Tenth }=7.21, \sigma \text { Tenth }=1.64\end{array}$ & \\
\hline Eighth grade & 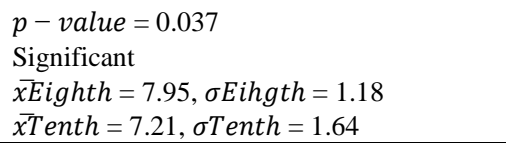 & 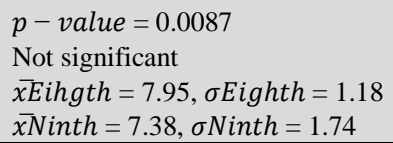 \\
\hline \multicolumn{3}{|c|}{ Pairwise T-Test second academic period } \\
\hline & Tenth grade & Ninth grade \\
\hline Ninth grade & $\begin{array}{l}p-\text { value }=0.00038 \\
\text { Significant } \\
\overline{x N \text { inth }}=9.12, \text { } \text { N Ninth }=0.78 \\
\bar{x} \text { enth }=8.34, \text { oTenth }=0.74\end{array}$ & \\
\hline Eighth grade & 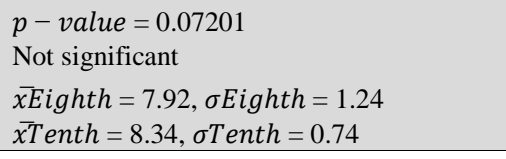 & 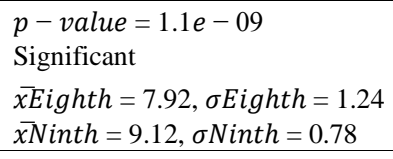 \\
\hline \multicolumn{3}{|c|}{ Pairwise T-Test thrid academic period } \\
\hline & Tenth grade & Ninth grade \\
\hline Ninth grade & $\begin{array}{c}p-\text { value }=0.0064 \\
\text { Significante } \\
\overline{x N \text { inth }}=7.61, \text { } \text { oNinth }=1.29 \\
\bar{x} \text { Tenth }=8.25, \text { } \text { \%Tenth }=0.65\end{array}$ & \\
\hline Eighth grade & 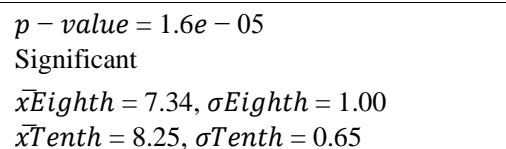 & $\begin{array}{l}p-\text { value }=0.5087 \\
\text { Not significant } \\
\overline{x E \text { ighth }}=7.34, \sigma \text { Eighth }=1.00 \\
\bar{x} \text { inth }=7.61, \text { oNinth }=1.29\end{array}$ \\
\hline
\end{tabular}

Table 5. MANOVA test applied to eighth, ninth and tenth grade students.

\begin{tabular}{|c|c|c|c|c|c|c|}
\hline Multivariate Tests Mark & Df & Test stat & Approx F & Num Df & Den Df & $\operatorname{Pr}(>\mathbf{F})$ \\
\hline Pillai & 2 & 0.3965706 & 11.29458 & 6 & 274 & 2.8353e-11*** \\
\hline Wilks & 2 & 0.6348888 & 11.56097 & 6 & 272 & $1.5838 \mathrm{e}-11^{* * *}$ \\
\hline Hotelling-Lawley & 2 & 0.5255278 & 11.82438 & 6 & 270 & 8.9436e-12*** \\
\hline Roy & 2 & 0.4023841 & 18.37554 & 3 & 137 & $4.4538 \mathrm{e}-10^{* * *}$ \\
\hline Signif. codes: & 0 & $\begin{array}{ll}\text { ‘***, } & 0.001\end{array}$ & $\begin{array}{ll}\text { ‘**, } & 0.01\end{array}$ & 0.05 & ‘' & ', 1 \\
\hline
\end{tabular}

Table 6. ANOVA Uni-varied analysis and Levene tests applied in each grade performance scores

\begin{tabular}{|c|c|c|c|c|c|c|c|}
\hline \multicolumn{8}{|c|}{ Levene's test for Homogeneity of Variance (center = mean) } \\
\hline Factor & DFn / DFd & $\mathrm{F}$ & p-value & $\mathrm{p}<0.05$ & $\mathrm{~F}$ & p-value & $\mathrm{p}<0.05$ \\
\hline $\begin{array}{l}\text { Eighth grade - } \\
\text { grading period }\end{array}$ & $2 / 138$ & 3.126298 & $0.04700303 *$ & Significant & 3.719611 & $0.04024853^{*}$ & Significant \\
\hline Factor & DFn / DFd & $\mathrm{F}$ & p-value & $\mathrm{p}<0.05$ & $\mathrm{~F}$ & p-value & $\mathrm{p}<0.05$ \\
\hline $\begin{array}{l}\text { Ninth grade - } \\
\text { grading period }\end{array}$ & $2 / 138$ & 20.94437 & $1.138631 \mathrm{e} 08^{* * *}$ & Significant & 12.33741 & $1.176402 \mathrm{e} 05^{* * *}$ & Significant \\
\hline Factor & DFn / DFd & $\mathrm{F}$ & p-value & $\mathrm{p}<0.05$ & $\mathrm{~F}$ & $\mathrm{p}$-value & $\mathrm{p}<0.05$ \\
\hline $\begin{array}{l}\text { Tenth grade - } \\
\text { grading period }\end{array}$ & $2 / 138$ & 11.85489 & $1.067601 \mathrm{e} 05^{* * *}$ & Significant & 11.26434 & $2.941202 \mathrm{e} 05^{* * *}$ & Significant \\
\hline $\begin{array}{l}\text { Significance } \\
\text { codes: }\end{array}$ & & 0 & 0.001 & ‘**, & ‘*’ & 0.1 & 1 \\
\hline
\end{tabular}


Table 7. Pairwise T-Test applied to first, second and third grades Middle School students performance results

\begin{tabular}{|c|c|c|}
\hline \multicolumn{3}{|c|}{ Pairwise T-Test eighth grade students performance } \\
\hline & First academic period & Second academic period \\
\hline Second period & $\begin{array}{c}p-\text { value }=0.83 \\
\text { Not significant } \\
\bar{x} \text { Second }=7.95, \text { oSecond }=1.16 \\
\bar{x} \text { First }=7.76, \text { } \text { First }=1.24\end{array}$ & \\
\hline Thrid period & $\begin{array}{c}p-\text { value }=0.289 \\
\text { Not significant } \\
\bar{x} \text { Third }=7.37, \text { } \text { Third }=1.04 \\
\bar{x} \text { First }=7.76, \text { } \text { First }=1.24\end{array}$ & $\begin{aligned} p- & \text { value }=0.047 \\
& \text { Significant } \\
\bar{x} \text { Third }= & 7.37, \text { oThird }=1.04 \\
\bar{x} \text { Second }= & 7.95, \text { oSecond }=1.16\end{aligned}$ \\
\hline \multicolumn{3}{|c|}{ Pairwise T-Test ninth grade students academic performance } \\
\hline & First academic period & Second academic period \\
\hline Second period & $\begin{array}{c}p-\text { value }=1.1 e-07 \\
\text { Significant } \\
\bar{x} \text { Second }=9.08, \text { oSecond }=0.79 \\
\bar{x} \text { First }=7.41, \text { oFirst }=1.77\end{array}$ & \\
\hline Third period & $\begin{array}{c}p-\text { value }=0.81 \\
\text { Nor significant } \\
\bar{x} \text { Third }=7.56, \text { } \sigma \text { Third }=1.42 \\
\bar{x} \text { First }=7.41, \text { } \text { FFirst }=1.77\end{array}$ & $\begin{array}{c}p-\text { value }=1.1 e-06 \\
\text { Significant } \\
\bar{x} \text { Third }=7.56, \sigma \text { Third }=1.42 \\
\bar{x} \text { Second }=9.08, \text { oSecond }=0.79\end{array}$ \\
\hline \multicolumn{3}{|c|}{ Pairwise T-Test tenth grade students performance } \\
\hline & First academic period & Second academic period \\
\hline Second period & $\begin{array}{c}p-\text { value }=3 e-05 \\
\quad \text { Significant } \\
\bar{x} \text { Second }=8.39, \text { } \text { SSecond }=0.76 \\
\bar{x} \text { First }=7.39, \text { ofirst }=1.54\end{array}$ & \\
\hline Third period & $\begin{array}{c}p-\text { value }=0.00031 \\
\text { Significant } \\
\bar{x} \text { Third }=8.26, \text { } \text { \%Third }=0.66 \\
\bar{x} \text { First }=7.39, \text { } \text { First }=1.54\end{array}$ & $\begin{array}{c}p-\text { value }=0.75 \\
\text { Not significant } \\
\bar{x} \text { Third }=8.26, \sigma \text { Third }=0.66 \\
\bar{x} \text { Second }=8.39, \text { oSecond }=0.76\end{array}$ \\
\hline
\end{tabular}

Table 5 reveals the existence of significative differences between factors and Roy's Largest Root significance found in the MANOVA suggests executing aunivariate study. ANOVA analysis was applied to each variable, which confirmed that there are differences found in every middle school student mark stratum. Finally, the Pairwise T-Test analysis was executed to establish each grade academic performance indicators, resulting in eighth graders' academic performance in the third grading period is better than second period (0.047 p-value). Conversely, ninth graders performance pertaining to the second period is higher than the one obtained in the third academic period followed by the performance of the first grading period (1.1e-06 and 1.1e-07 p-values respectively). In the case of tenth graders, second grading period performance was higher compared to the first period and third period performance shows higher values in contrast to the first period (3e-05 and 0.00031 p-values respectively).

\section{Results}

The diagnosis carried out through the survey demonstrates that, teachers at general basic education level use basic technological tools for content presentation, since the institution is located in the rural sector where there are internet access limitations Consequently, the most used software are power point and prezzi. Additionally, it was detected that the used pedagogic tools almost completely consist of teacher's demonstration and as a final learning product manual work carried out by students is used in order to obtain a quantitative assessment that often puts the learning process at risk.

Based on the aforementioned, the weights in Table 5 indicate the score of the four factors that determined that, the development and implementation of the multimedia instructional module at Educational Institution Eugenio Espejo, achieved promising scores. For example, based on the student's opinion it was a high percentage for the subject importance factor obtained, verifying that teaching and learning while respecting learning styles contributes to improve their grades.

Table 5 exhibits 4-factor weighted scores which determined the types of practice that students consider suitable for enhanced learning in addition to the need for an instructional module implementation.

Table 8. Final sample weighted scores survey outcome

\begin{tabular}{cc}
\hline Need for implementation & $78.28919 \%$ \\
\hline Academic subject relevance & $80.00483 \%$ \\
\hline Pedagogic Practice & $78.23277 \%$ \\
\hline Academic performance & $79.88354 \%$ \\
\hline
\end{tabular}


In addition, the survey allowed us to determine that an improvement in academic performance is also admissible for people who study and work at the same time, without parents' support, this due to socioeconomic factors that influences the sector. Finally, it was proven that the use of technological tools and social networks backs learning worth to be implemented even in regions with limited internet access, because students tend to be curious about new experiences and this could be used as an opportunity for implementing educational technology.

ExeLearning INTEF-eXe Project version 2.2 software was selected for the development of the instructional module because of its simplicity of navigability. This is an open-source software which allows the creation of educational content trees, where you can insert multimedia material, small evaluations or load educational activities developed in other applications and any kind of task that the student develops. One of the advantages offered by the software, at the creation or customization of the interface, is its customizability that in the present research allowed the module to be adapted for young adolescents from 12 to 15 years.

The analysis of the results before and after applying the multimedia instructional module was performed by comparing the averages of the summative evaluation of each partial. Figure 4 reveals the significance between data in each grade, which in turn indicates that in first academic period there is no change in marks because of the limited use of software in addition to the implementation of lectures which notably diminished students' motivation. In contrast to the second academic period, the instructional design module includes topics and activities like dance, music and theatre that go accordingly to the kinaesthetic leaning that most students own as illustrated by higher significance levels.

In the third academic period, first and second grade students learn subjects that demand creativity and reflexive- thought, so significance levels are kept high. While third graders' difficulty levels on planned skills suggest the creation of autonomous multimedia material.

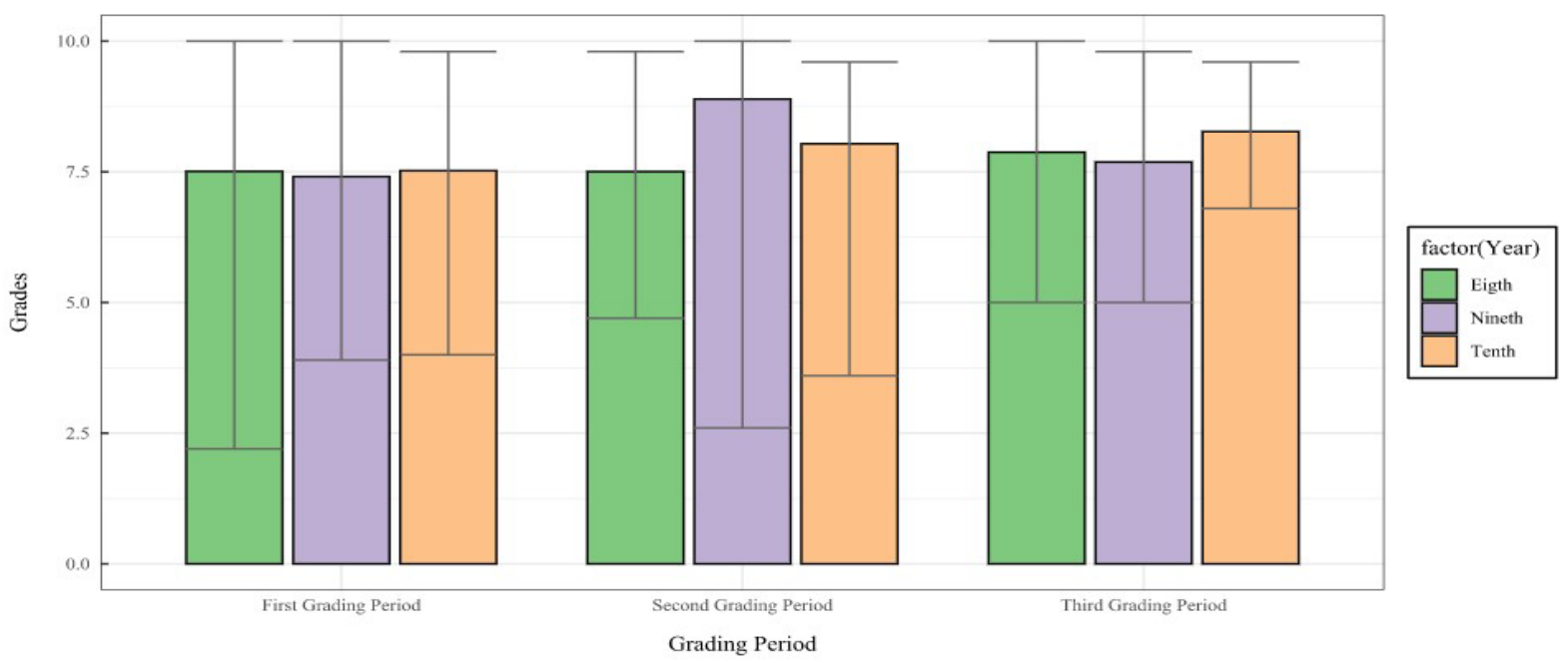

Figure 4. Marks according to academic period having implemented the instructional module

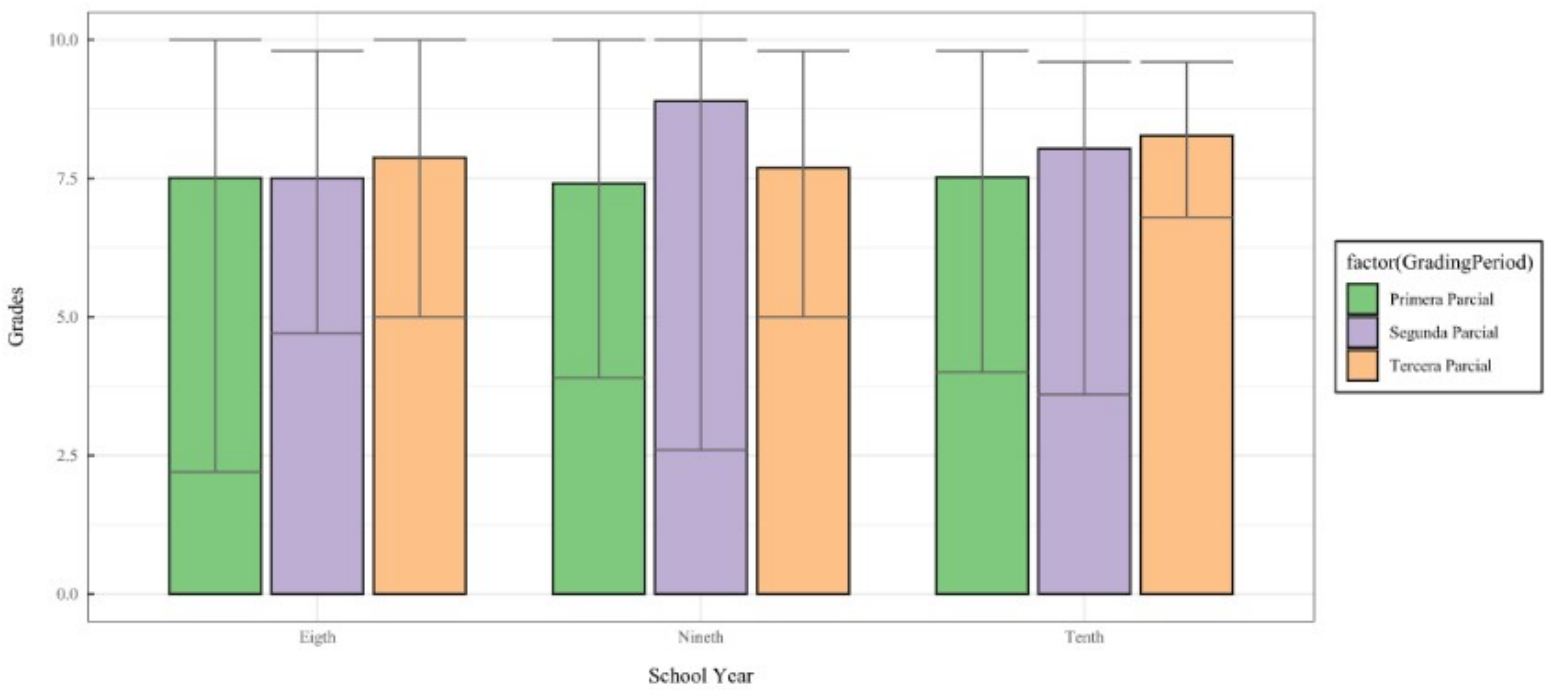

Figure 5. Marks byacademicyear, a partir de la implementación del módulo instruccional 
The academic period analysis-Figure 5-indicated equal significance levels from first grade students with light significance, whereas second grade students' first period performance generates higher significance levels because of the integration of Ecuadorian folklore mixed with pop music in class. Finally, third grade students' third academic period shows a continuous progress as a result from theater-days audiovisual artsy creations, music mixes and the like. It is even believed that this progress is related to students' academic maturity.

\section{Conclusions}

The established pedagogical practices allow students to acquire content, while pedagogical practices together with educational technological tools expose the student to interesting ways of acquiring knowledge and motivating them to discover multiple learning platforms. In this way, the technological gap that exists between an urban sector and a rural sector, will be smaller, perfecting the teaching-learning processes with students who acquire technological skills in an increasingly hasty way.

The development of tan instructional module through the ADDIE model includes a complete process which facilitated planning in the environment of exeLearning, since it is not necessary to be designed by an expert in HTML or XML. This process verified the progress of the students in a quantitative manner.

The educational technologies and issues contextualized to each institution according to their learning style, generate curiosity, creativity and a proactive attitude which help to solve academic problems and at the same time achieve significative schooling that can be verified in summative and formative evaluations.

\section{REFERENCES}

[1] Fernández.M, «Towards pedagogy, contribution differences from Paulo Freire's proposal», Paulo Freire. Contrib. para la Pedagog., pp. 341-348, 2008.

[2] Chicaiza. T, «Appliedpedagogicpracticeon Social Sciences at " Unidad Educativa Primicias de la Cultura de Quito», 2013.

[3] Republicof Ecuador Constitution «Constitucion de la republica del Ecuador 2008», OfficialRecord 449. pp. 1-136, 2008, doi: 10.1017/CBO9781107415324.004.

[4] Education Ministry«Pedagogic guidelines for the use of open education digital resources in learning processes», $J$. Chem. Inf. Model., vol. 53, n. ${ }^{\circ}$ 9, pp. 1689-1699, 2019, doi: 10.1017/CBO9781107415324.004.

[5] Telecommunication and Information Society Ministry « Information and Knowledge Society Plan», p. 91, 2018.
[6] McGonigle-Chalmers. M, and Kusel. I, «The Development of Size Sequencing Skills: An Empirical and Computational Analysis», Monogr. Soc. Res. Child Dev., vol. 84, n. ${ }^{\circ}$ 4, pp. 7-202, 2019, doi: 10.1111/mono.12411.

[7] Moradi. M, Liu. L, Luchies. C, Patterson.M.M, and Darban. $\mathrm{B}$, «Enhancing teaching-learning effectiveness by creating online interactive instructional modules for fundamental concepts of physics and mathematics», Educ. Sci., vol. 8, n. ${ }^{\circ}$ 3, 2018, doi: 10.3390/educsci8030109.

[8] Lau. K.H.V, «Computer-based teaching module design: Principles derived from learning theories», Med. Educ., vol. 48, n. ${ }^{\circ}$ 3, pp. 247-254, 2014, doi: 10.1111/medu.12357.

[9] Ong. C. P, and Tasir. Z, «Self-instructional module based on cognitive load theory: A study on information retention among trainee teachers", Educ. Technol. Res. Dev., vol. 63, n. ${ }^{\circ}$ 4, pp. 499515, ago. 2015, doi: 10.1007/s11423-015-938 3-8.

[10] Cain. J, «Exploratory implementation of a blended format escape room in a large enrollment pharmacy management class», Curr. Pharm. Teach. Learn., vol. 11, n. ${ }^{0}$ 1, pp. 44-50, 2019, doi: 10.1016/j.cptl.2018.09.010.

[11] Mustafa. A and Hatemi-J. A, «A VBA module simulation for finding optimal lag order in time series models and its use on teaching financial data computation», Appl. Comput. Informatics, . $^{\circ} \mathrm{xxxx}, 2019$, doi: 10.1016/j.aci.2019.04.003.

[12] Artola. V and Sanz. C, «Learning Object for the understanding of the operation merge», 12th Lat. Am. Conf. Learn. Objects Technol. LACLO 2017, pp. 3-6, 2017.

[13] Prasetyani. I, Darojah. D. M, Novianti. N, and Sulisworo.D, «Developing eXeLearning application through project-based learning», J. Phys. Conf. Ser., vol. 1188, n. ${ }^{\circ} 1$, 2019, doi: 10.1088/17426596/1188/1/012068.

[14] Rokhima. N, Harisna. B. L, Ningrum I. E, and Sulisworo.D, «The eXeLearning for social arithmetics through scientific approach», J. Phys. Conf. Ser., vol. 1188, n. ${ }^{\circ}$ 1, 2019, doi: 10.1088/1742-6596/1188/1/012056.

[15] Minuti. A, Sorensen. K, Schwartz. R, King. W. S, Glassman. N. R, and Habousha. G, «Librarians Flip for Students: Teaching Searching Skills to Medical Students Using a Flipped Classroom Approach», Med. Ref. Serv. Q., vol. 37, n. ${ }^{\circ}$ 2, pp. 119-131, 2018, doi: 10.1080/02763869.2018.143 9184.

[16] Planning and Development Department, «Development National Plan 2017-2021-A whole life program», p. 84, 2017.

[17] Education Ministry, Mandatory education levels program.

[18] Education Ministry, «The Arts and Culture Education programs », Curriculo, p. 164, 2016.

[19] Patel. S. R, Margolies. P. J, Covell. N. H, Lipscomb. C, and Dixon L. B., «Using Instructional Design, Analyze, Design, Develop, Implement, and Evaluate, to Develop e-Learning Modules to Disseminate Supported Employment for Community Behavioral Health Treatment Programs in New York State», Front. Public Heal., vol. 6, n. ${ }^{\circ}$ May, 2018, doi: 10.3389/fpubh.2018.00113.

[20] Field A, Miles. J, and Field.Z, Discovering Statistics Using 
$R$, vol. 165, n. ${ }^{\circ} 3.2016$.

[21] López. S. U, «TICs inclusion dimensions in education programs: A theoretical approximation», Teor. la Educ., vol. 28, n. ${ }^{\circ}$ 1, pp. 209-223, 2016, doi: 10.14201/teoredu201628 1209223.

[22] Jácome. A, Herrera. E, Caraguay. J y Herrera. I, «Confirmatory Factorial Analysis Applied on Teacher Evaluation Processes in Higher Education Institutions of
Ecuador,» Advances in Intelligent Systems and Computing, pp. 157-170, 2020.

[23] Jácome. A, Herrera. E, Herrera. I, Caraguay. J, Basantes. A y Ortega. M, «Análisis temporal y pronóstico del uso de las TIC, a partir del instrumento de evaluación docente de una Institución de Educación Superior,» ISTI - Revista Iberica de Sistemas e Tecnologias de Informacao, vol. E22, pp. 399412, 2019. 